\title{
Prolonged reduction in polymorphonuclear adhesion following oral colchicine
}

\author{
J. N. FORDHAM, J. KIRWAN, J. CASON, AND H. L. F. CURREY \\ From the Bone and Joint Research Unit, the London Hospital Medical College, and the Department of \\ Rheumatology, the London Hospital
}

SUMMARY Polymorphonuclear leucocyte (PMN) function was studied in 7 healthy subjects before and after $5 \mathrm{mg}$ of colchicine taken in divided doses over 24 hours. Mean adherence to nylon fibre colums fell from a pretreatment level of $51 \%$ to $33.6 \%$ by day 1 , remained low $(31 \cdot 8 \%)$ at day 5 , and returned to pretreatment levels only by about day 9 . Random motility (agarose plate method) fell from $932 \mu \mathrm{m}$ to $688 \mu \mathrm{m}$ by day 1 , but had returned to normal by day 5 . Directed migration and the phagocytic index (opsonised Candida albicans method) were not affected by colchicine treatment. In view of the fact that the plasma half life of colchicine is 19 minutes and that of PMN only 7 hours, this marked and prolonged reduction in PMN adhesion implies an influence on maturing PMN precursors in bone marrow. Adherence to nylon fibres may reflect in-vivo properties of PMN which are important in the pathogenesis of acute gouty arthritis.

Although colchicine has been used for over a century in the prophylaxis and treatment of acute gout, the mode of action of this drug has not been clearly defined. Following the work of $\mathrm{McCarty}^{1}$ it is generally accepted that the polymorphonuclear leucocyte (PMN) is the chief cell concerned in the inflammatory response mounted against urate crystals. Most work on colchicine has centred on its effect on this cell. Such studies have generally employed in-vitro systems to test the effect of the drug on various aspects of PMN function. These often involved such high concentrations of the drug as to make the clinical relevance of any findings dubious. ${ }^{2}$ Because of this we have followed 3 aspects of PMN function in volunteers given colchicine within the dosage range used in acute gout.

\section{SUBJECTS AND METHODS}

Healthy male laboratory and medical staff took $5 \mathrm{mg}$ of colchicine orally in divided doses over 24 hours. Blood samples were taken into heparinised containers (10 IU heparin $/ \mathrm{ml}$ ) on the morning prior to the first dose and subsequently each morning.

Cell preparation. Heparinised whole blood was used for the adherence studies. For the other studies

Accepted for publication 15 January 1981

Correspondence to $\mathrm{Dr}$ J. N. Fordham, Bone and Joint Research Unit, London Hospital Medical College, Arthritis and Rheumatism Council Building, 25-29 Ashfield Street, London E1 2AD. purified PMN were prepared by a Hypaque-Ficoll separation procedure. ${ }^{3}$ Cells were washed 3 times in 199 culture medium with $1 \%$ human serum albumin (AB KABI Stockholm) with $\mathrm{NaHCO}_{3} 350 \mathrm{mg} / \mathrm{ml}$, 500 units penicillin $/ \mathrm{ml}$, and $500 \mu \mathrm{g}$ streptomycin $/ \mathrm{ml}$.

PMN adhesion was measured by a modification of Stecher and Chinea's method. ${ }^{4}$ Plungers were removed from $1 \mathrm{ml}$ disposable syringes, which were then packed with $20 \mathrm{mg}$ of scrubbed nylon fibre (Fenwal Labs, USA) to the $0 \cdot 1 \mathrm{ml}$ mark and clamped in the vertical position. A $25 \mathrm{G}$ disposable needle was fitted and the syringe warmed to $37^{\circ} \mathrm{C}$ prior to introducing $300 \mu$ l of heparinised whole blood into the open end of the syringe. The plunger was then reintroduced and advanced until the bottom of the column of blood reached the bottom of the nylon fibre column. After incubation at $37^{\circ} \mathrm{C}$ for 10 minutes the blood was expelled by gentle pressure on the plunger, leaving adherent cells on the nylon column. White cell counts were carried out on the original and effluent samples with a Coulter electronic particle counter and differential white cell counts on a Leishman stain of blood smears. Adherence was expressed as a percentage of PMN retained in the column. All tests were performed in triplicate.

Motility studies were carried out by the agarose plate method described by Repo. ${ }^{5}$ Agarose (Marine Colloids Inc, USA) was dissolved in distilled water 
heated in a water bath at $60^{\circ} \mathrm{C}$. The agarose solution was allowed to cool to $45^{\circ} \mathrm{C}$ and added to an equal volume of diluted 199 medium containing human serum albumin, penicillin, and streptomycin. Sodium bicarbonate was then added to give the following concentrations: $1 \%$ albumin, $350 \mathrm{mg} / \mathrm{ml}$ $\mathrm{NaHCO}_{3}, 500$ units penicillin/ml, $500 \mu \mathrm{g}$ streptomycin $/ \mathrm{ml} .8 .5 \mathrm{ml}$ of this solution was decanted into tissue culture plates $(85 \times 10 \mathrm{~mm}$; Sterilin Products, Teddington, UK) and allowed to harden by refrigeration at $4^{\circ} \mathrm{C}$ for 30 minutes. Wells were cut $2 \mathrm{~mm}$ apart in the agarose film with a $3 \mathrm{~mm}$ skin punch biopsy punch (Steifel Laboratories, UK). The chemoattractant used was zymosan-activated pooled human serum prepared by adding $100 \mu$ l of zymosan suspension $(10 \mathrm{mg} / \mathrm{ml}$ in saline) to $500 \mu \mathrm{l}$ of pooled human serum. $7 \mu \mathrm{l}$ of zymosan-activated serum was placed in one well. One hour later $2.5 \times 10^{5}$ purified PMN was added to the opposite well and the plates incubated in a humidified incubator with $4 \% \mathrm{CO}_{2}$ for $2 \frac{1}{2}$ hours. The cells were then fixed by pouring $100 \%$ methanol on to the plates and leaving for at least 1 hour. Next the agarose gel was peeled off leaving the cells adherent to the plates. After drying, the cells were stained with toluidine blue. Migration distances were measured to the leading cell by an electronic micrometer attached to the microscope stage. Random motility was similarly measured on separate tissue culture plates from which chemotaxins were excluded. All experiments were carried out in quadruplicate.

Phagocytosis was measured by a modification of Lehrer and Cline's method. ${ }^{6}$ Heat killed candida blastospores were washed 3 times, then opsonised by incubation with $20 \%$ pooled $\mathrm{AB}$ serum for 30 minutes. $500 \mu \mathrm{l}$ of purified PMN was added to an equal volume of candida suspension and incubated for 1 hour. The final concentration of PMN was $10000 \mu \mathrm{l}$ and candida $90000 / \mu \mathrm{l}$. Phagocytosis was stopped by adding $0 \cdot 1 \mathrm{M}$ iodoacetate. One hundred consecutive PMN were examined on smears stained with methylene blue. Phagocytosis was assessed as the mean number of candida per PMN (phagocytic index). Each experiment was carried out in duplicate.

Statistical evaluation was by a paired $t$ test.

\section{Results}

ADHERENCE (Fig. 1, Table 1)

There was a reduction in the percentage adherent PMN in all subjects following colchicine. Mean values fell from $51 \%$ precolchicine to $33.6 \%$ on day $1(\mathrm{p}<0.005)$ and this reduction was maintained at day 5 (mean $31 \cdot 8 \% \mathrm{p}<0.005$ ). The time taken to return to precolchicine values ranged from 5 to 16 days, with a mean of 9 days.

MOTILITY STUdies (Fig. 2, Table 2)

Directed migration did not alter significantly afte

Table 1 Change in PMN adherence following colchicine (mean $\% \pm S D$ ). Values of $p$ calculated from paired $\mathrm{t}$ test

\begin{tabular}{llll}
\hline Before colchicine & \multicolumn{4}{l}{ Days after colchicine } \\
\cline { 2 - 4 } & 1 & 5 & 8 \\
\hline $51 \cdot 0(8 \cdot 7)$ & $33.6(13 \cdot 2)^{*}$ & $31 \cdot 8(15 \cdot 3)^{*}$ & $42 \cdot 8(19 \cdot 3) \ddagger$ \\
\hline
\end{tabular}

*Significantly different from precolchicine value $\mathrm{p}<0.005$. $\ddagger$ Not significantly different from precolchicine value.

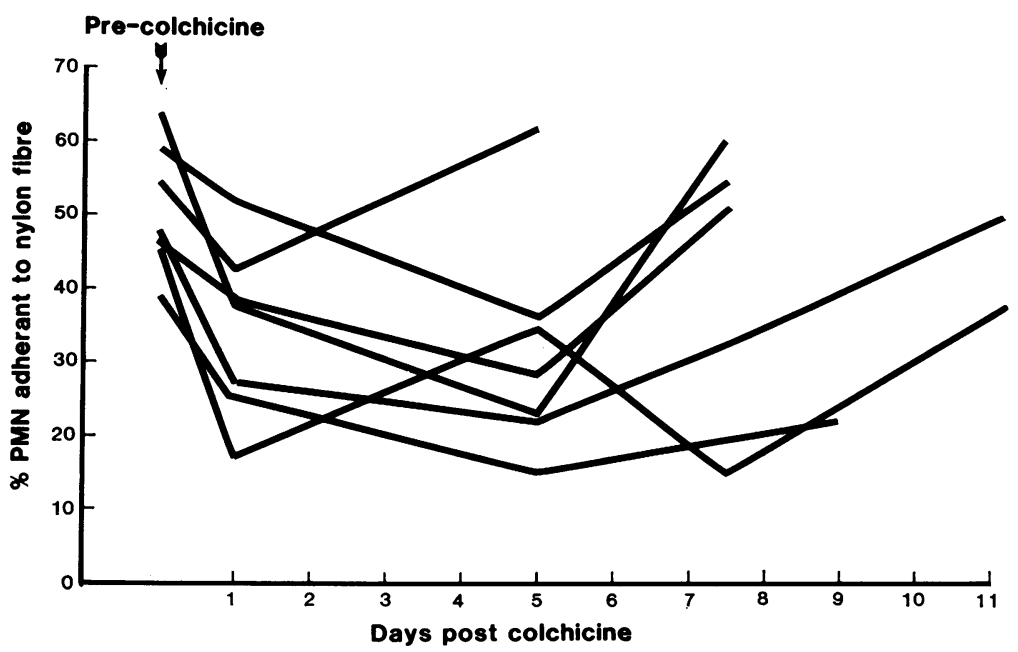

Fig. 1 Change in PMN adherence following colchicine (percentage cells adherent to nylon fibre). Each line represents one subject. 


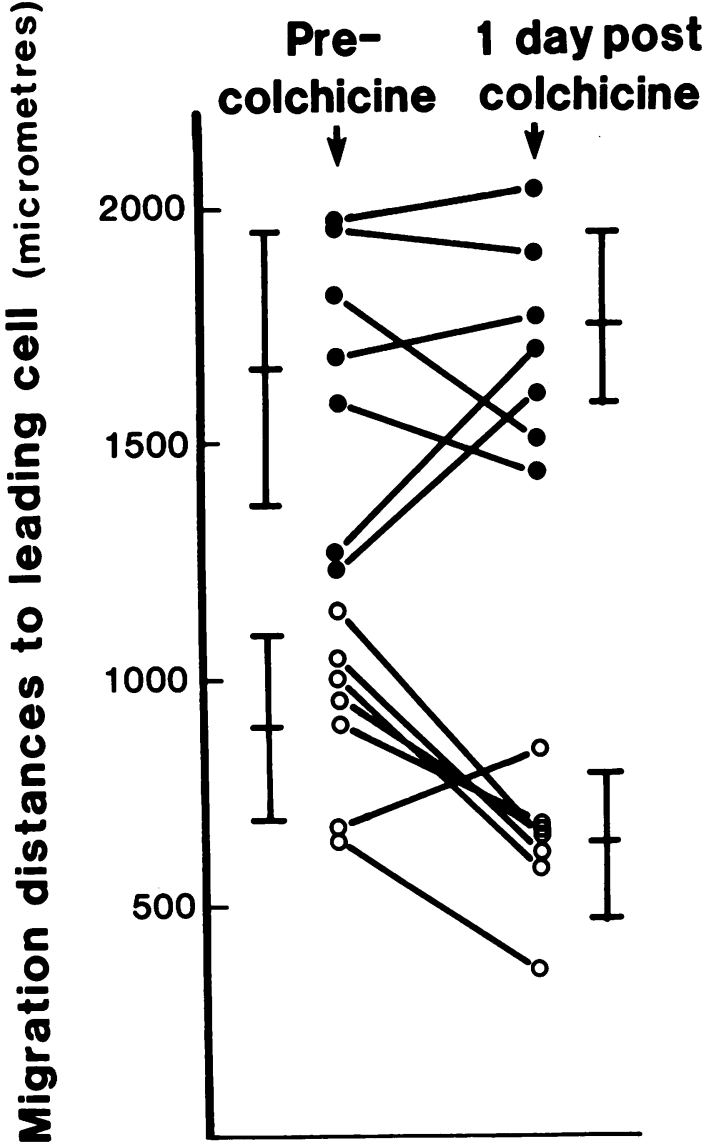

Fig. 2 Changes in PMN motility following colchicine. Agarose plate method single cell leading front measurement. $\mathbf{O}=$ random migration. 0 directed migration measurements in microns $\pm 1 S D$.

Table 2 Changes in PMN motility following colchicine (mean distances in $\mu m \pm S D$ ) for single cell leading front using agarose plates

\begin{tabular}{lccr}
\hline & Precolchicine & \multicolumn{2}{l}{ Days postcolchicine } \\
\cline { 3 - 4 } & & 1 & 5 \\
\hline Directed & $1767(348)$ & $1788(192)$ & $1853(253)$ \\
Random & $932(190)$ & $688(176)^{*}$ & $893(194)$ \\
\hline
\end{tabular}

*Significantly different from precolchicine value, $\mathrm{p}<0.01$.

Table 3 Change in phagocytic index after colchicine (mean number of blastospores per $P M N \pm S D$ )

\begin{tabular}{lll}
\hline Precolchicine & \multicolumn{2}{l}{ Days postcolchicine } \\
\cline { 2 - 3 } & 1 & 5 \\
\hline $4.96(0.86)$ & $4.71(0.5)^{*}$ & $4.83(0.61)^{*}$ \\
\hline
\end{tabular}

*Not significantly different from precolchicine value. colchicine. However, random migration fell from a mean of $932 \pm 190 \mu \mathrm{m}$ precolchicine to 688 $\pm 176 \mu \mathrm{m}$ at day $1(\mathrm{p}<0 \cdot 01)$. By day 5 there was no significant difference from the precolchicine level.

PHAGOCYTOSIS (Table 3)

There was no change in the phagocytic index immediately following colchicine or at day 5 .

\section{Discussion}

We have shown that colchicine, within the dosage used in the treatment of acute gout, causes a marked and persistent reduction in PMN adherence assessed in an in-vitro test. Since the plasma half life of colchicine is 19 minutes $^{2}$ and that of PMN only 7 hours, ${ }^{7}$ this result can be explained only on the basis of uptake by bone marrow PMN precursors as well as circulating PMN at the time of taking the drug. This is in keeping with Ertel and Wallace's ${ }^{8}$ finding of significant levels of colchicine present in PMN at 9 days following a single intravenous dose of $3 \mathrm{mg}$. Previous $^{910}$ have demonstrated a reduction in adhesion after colchicine. However, this was reported as short-lived, lasting only 6 hours in MacGregor's study. ${ }^{10}$ Two of the 3 subjects whom Perry et al. reported on ${ }^{9}$ showed a drop in adhesion following $5.5 \mathrm{mg}$ of oral colchicine at 4 hours, which was maintained 8 hours after taking the drug. One of these subjects still had depressed adherence at 24 hours. In none of these studies was adherence measured after 24 hours. The differences between our findings and these others may relate to differences in methodology and dose of drug taken.

It seems likely that PMN adhesiveness to nylon fibre reflects the capacity of PMN to adhere to foreign surfaces generally. It is known that complement activators are released by PMN on contact with nonphagocytosable material such as nylon fibre. ${ }^{11} 12$ Thus, through the generation of complement products (chiefly C5a) which increase PMN adhesiveness, this test is also a reflection of PMN secretory function. This being the case, our findings would be compatible with either a drug-induced reduction in secretory function of PMN (and hence less local complement activation) or with an impaired adhesive response per se. It is pertinent to note in this regard that pretreatment of leucapheresis donors with colchicine has been shown to reduce lysosomal enzyme release when PMN are harvested on nylon fibre. ${ }^{13}$ Other workers have shown that colchicine reduces extracellular release of granular enzymes ${ }^{14}$ and uric acid crystal-induced chemotactic factor. ${ }^{15}$ It has been suggested that 
PMN-nylon fibre interactions mirror PMN-endothelial interactions. ${ }^{16}$ If so, it may be that the efficacy of the drug in preventing or ending acute gout may be due to interference with PMN adhesion to endothelium and thus reduction in the egress of PMN towards the joint cavity. Reduced release of crystal-induced chemotactic factor ${ }^{15}$ or complement-activating enzymes could be other mechanisms reducing PMN recruitment.

We have been unable to show any impairment in directed PMN motility following colchicine. This in keeping with the work of Pinarello et al., ${ }^{17}$ who found no change in the chemotactic response of PMN of patients taking colchicine for familial Mediterranean fever. It also concurs with Allan and Wilkinson's suggestion ${ }^{18}$ that colchicine affects the turning ability of the cell without altering its response to a chemoattractant. It is not clear whether or how reduced random motility in vivo might relate to the efficacy of colchicine in gout, although it is conceivable that the property of nondirected random motility is also necessary for the PMN to play its full role in urate crystal induced inflammation.

The lack of effect of the drug on phagocytosis of Candida albicans is in keeping with previous in-vivo findings. ${ }^{917}$ Spilberg et al. ${ }^{15}$ noted that although release of a urate-crystal-induced chemotactic factor was impaired by colchicine, phagocytosis per se was not impaired.

The most interesting finding in this study is the surprisingly prolonged effect of the drug on what is probably an important aspect of PMN function, namely, adhesion. It suggests that prophylaxis of acute gout may be achieved by very much less frequently administered doses of colchicine.

If PMN adherence to endothelium is the critical factor in the action of colchicine in acute gout, this does not explain the specificity of the drug in this condition. Only the urate-crystal-induced chemotactic factor hypothesis ${ }^{15}$ invokes a mechanism unique to gout. On the other hand it is conceivable that the very acuteness of urate crystal synovitis is what makes it to some extent 'unique.' If so, endothelial adherence of PMN could be the critical factor susceptible to colchicine.

This work was supported by an Arthritis and Rheumatism Council grant. Dr John Fordham was in receipt of an Arthritis and Rheumatism Council research fellowship.

\section{References}

1 McCarty D J. The inflammatory reaction to microcrystalline sodium urate. Arthritis Rheum 1965; 8: 726-35.

2 Wallace S L. Onokoku B, Ertel N. Colchicine plasma levels: implications as to pharmacology and mechanisms of action. Am J Med 1970; 48: 443-8.

3 Ferrante A, Thong Y H. A rapid one-step procedure for purification of mononuclear and polymorphonuclear leukocytes from human blood using a modification of the Hypaque-Ficoll technique. J Immunol Methods 1978 ; 24: 389-93.

4 Stecher V, Chinea G L. The neutrophil adherence assay as a method for detecting unique anti-inflammatory agents. Agents Actions 1978; 8: 259-62.

5 Repo H. Leukocyte migration agarose test for the assessment of human neutrophil chemotaxis. I. Effects of environmental factors on neutrophil migration under agarose. Scand J Immunol 1977; 6: 203-9.

6 Lehrer R I, Cline M J. Interaction of candida albicans with human leukocytes and serum. J Bacteriol 1969; 100: 996-1004.

7 Dancey J T, Deubelbeiss K A, Harker L A, Finch L A. Neutrophil kinetics in man. J Clin Invest 1976; 58: 705-15.

8 Ertel N H, Wallace L. Measurements of colchicine in plasma and peripheral leukocytes. Clin Res 1971; 19: 348 (abstr).

9 Perry R, Galton D A G, Scott J T, Eisen V. Studies in neutrophil function. I: Physiological and pharmacological aspects. Br J Haematol 1966; 12: 623-32.

10 MacGregor R R. The effect of anti-inflammatory agentso and inflammation on granulocyte adherence. Evidence for regulation by plasma factors. Am J Med 1976; 61 597-607.

11 Gallin J I, Quie P G. Leukocyte Chemotaxis. New York:Rowen Press, 1978: 225.

12 Wright D G, Kauffmann J C, Tempstra G K, Grow R G, Reisseroth A B, Gallin J I. Mobilization and exocytosis of specific (secondary) granules by human neutrophils during adherence to nylon wool, in filtration leukophoresis (FL). Blood 1978; 52: 770-82.

13 Wright D G, Ungerleider R S, Gallin J I, Reisseroth A B. Pretreatment of filtration leukophoresis donors with colchicine. Blood 1978; 52: 783-92.

14 Wright D G, Malawista S E. Mobilization and extracellular release of granular enzymes from human leukocytes during phagocytosis: inhibition by colchicine and cortisol but not by salicylate. Arthritis Rheum 1973; 16: 749-58.

15 Spilberg J A, Gallacher J M, Menta J M, Mandell B. Urate crystal induced chemotactic factor. Isolation and partial characterization. J Clin Invest 1976; 58: 815-9.

16 MacGregor R R, Macarak E J, Kefalides W A. Comparative adherence of granulocytes to endothelial monolayers and nylon fibre. J Clin Invest 1978; 61 : 697-702.

17 Pinarello C A, Chusid M J, Fauci A S, Gallin J I, Dale D C, Wolff S M. Effect of prophylactic colchicine therapy on leukocyte function in patients with familial Mediterranean fever. Arthritis Rheum 1976; 19: 618-23.

18 Allan R B, Wilkinson P C. A visual analysis of chemotactic and chemokinetic locomotion of human neutrophil leucocytes. Exp Cell Res 1978; 111 : 191-203. 